\title{
Impacto da implantação de um protocolo de transfusão de hemocomponentes em um hospital terciário do Sul do Brasil através de ferramenta de prescrição eletrônica
}

\author{
Pithan, C.F.; Siegle, A.L.; Moreno, F.L.; Polanczyk, C.A.; \\ Apresentador: Carolina da Fonte Pithan
}

\section{Resumo}

Introdução: Protocolos clínicos e diretrizes terapêuticas são frequentemente criados para auxiliar na prática clínica. Entretanto, não é incomum que diretrizes publicadas não sejam completamente seguidas, por inúmeros motivos. A adesão a protocolos transfusionais também não é ideal, apesar das últimas evidências na literatura apontarem para um uso cada vez mais restrito e mais racional do sangue reduzindo a exposição dos pacientes a riscos transfusionais desnecessários. Foram realizados dois estudos transversais, um antes e outro depois da implementação de um protocolo transfusional institucional através de ferramenta eletrônica vinculada à prescrição médica. Cada um dos períodos analisados foi de 30 dias consecutivos e, após, foram feitas comparações das características demográficas dos pacientes e do grau de adesão ao protocolo transfusional da instituição. Foram avaliadas 963 prescrições de hemocomponentes nos dois períodos estudados, a maioria delas de concentrado de hemácias $(73,3 \%)$, seguido de concentrado de plaquetas $(16,5 \%)$ e plasma fresco congelado $(10,2 \%)$. A ferramenta eletrônica foi capaz de aumentar a adesão ao protocolo transfusional de 62,9\% em 2011 para 75,9\% em 2012 ( $\mathrm{p}<0,0001)$, seis meses após a implantação da ferramenta eletrônica, especialmente nas especialidades cirúrgicas e medicina interna. $\mathrm{O}$ número de transfusões realizadas por paciente teve relação independente com a mortalidade hospitalar, embora a adesão ao protocolo transfusional não tenha demonstrado tal efeito. Intervenções consideradas relativamente simples, como a implementação de uma ferramenta junto à prescrição médica, podem aumentar de forma significativa as taxas de adesão a protocolos institucionais, otimizando recursos e melhorando progressivamente a qualidade assistencial e segurança dos pacientes atendidos. Entretanto, deve ainda ser avaliada a efetividade dessa intervenção a longo prazo e as medidas associadas a boas taxas de adesão ao longo dos anos.

\section{Referência:}

Pithan, C.F.; Siegle, A.L.; Moreno, F.L.; Polanczyk, C.A.; Impacto da implantação de um protocolo de transfusão de hemocomponentes em um hospital terciário do Sul do Brasil através de ferramenta de prescrição eletrônica. In: II Congresso Brasileiro de Medicina Hospitalar - II CBMH [= Blucher Medical Proceedings, vol.1, num.5] São Paulo: Editora Blucher, 2014. p.84

DOI 10.5151/medpro-II-cbmh-082 